Pesq. Vet. Bras. 28(3):161-168, março 2008

\title{
Fatores de risco associados à infecção pelo herpesvírus bovino 1 em rebanhos bovinos da região Oeste do Estado do Paraná1
}

\author{
Juliana A. Dias ${ }^{2}$, Amauri A. Alfieri ${ }^{3}$, Kerlei C. Médici ${ }^{3}$, Julio C. Freitas ${ }^{3}$, José S. \\ Ferreira $\mathrm{Neto}^{4}$ e Ernst E. Müller ${ }^{3^{*}}$
}

\begin{abstract}
Dias J.A., Alfieri, A.A., Medici, K.C., Freitas, J.C., Ferreira-Neto J.S. \& Müller E.E. 2008. [Risk factors for bovine herpesvirus 1 infection in cattle herds in the West region of Parana State.] Fatores de risco associados à infecção pelo herpesvírus bovino 1 em rebanhos bovinos da região Oeste do Estado do Paraná. Pesquisa Veterinária Brasileira 28(3):161-168. Departamento de Medicina Veterinária Preventiva, Universidade Estadual de Londrina. Rodovia Celso Garcia Cid 380, Cx. Postal 6001, Londrina, PR 86051-990, Brazil. E-mail: muller@uel.br

The aim of this study was to determine the prevalence of positive herds and to identify the risk factors for BoHV-1 infection in breeding cattle herds in the Western region of Parana State. The statistic delineation, the serum samples and information regarding the selected farms, were the same employed in the study of bovine brucellosis for Parana State in the context of National Program for Control and Eradication of Brucellosis and Tuberculosis. The sampling was performed in two stages. Blood samples were collected from 1930 females aged $\geq 24$ months from 295 non vaccinated herds. Serum samples were tested for antibodies against BoHV-1 using an indirect ELISA. The epidemiological questionnaire was applied on all the selected farms and aimed to obtain epidemiological data. Hundred ninety of the 295 herds were positive for BoHV-1, presenting prevalence of positive herds of $64.41 \%$ [58.65-69.87\%]. The number $(\geq 23)$ of females aged 24 months $(\mathrm{OR}=2.22$; IC: $1.09-4.51)$, purchased cattle (OR=2.68; IC: 1.48-4.82), use of common grass $(\mathrm{OR}=5.93$; IC: $1.31-26.82)$, history of abortion in the last 12 months (OR=2.37; IC: 1.09-5.16) and presence of wildlife animals $(\mathrm{OR}=8.86$; IC: $1.11-70.73)$ were identified as risk factors for BoHV-1 infection in the multivariate logistic regression. These results indicate that BoHV-1 infection is widespread in the studied region and that factors related to the herd characteristic and management are associated with the infection.
\end{abstract}

INDEX TERMS: Prevalence, epidemiology, risk factors, bovine herpesvirus 1, indirect ELISA.

RESUMO.- O objetivo deste estudo foi determinar a prevalência de rebanhos positivos (focos) e identificar os fatores de risco que possam estar associados com a in-

\footnotetext{
${ }^{1}$ Recebido em 11 de outubro de 2007.

Aceito para publicação em 8 de dezembro de 2007.

2 Programa de Pós-Graduação em Ciência Animal, Universidade Estadual de Londrina (UEL), Londrina, Paraná.

${ }^{3}$ Departamento de Medicina Veterinária Preventiva, UEL, Rodovia Celso Garcia Cid 380, Cx. Postal 6001, Londrina, PR 86051-990, Brasil. *Autor para correspondência: muller@uel.br

${ }^{4}$ Departamento de Medicina Veterinária Preventiva e Saúde Animal, Universidade de São Paulo (USP), Av. Prof. Dr. Orlando Marques de Paiva 87, Cidade Universitária, São Paulo, SP 05508-270, Brasil.
}

fecção pelo herpesvírus bovino 1 (BoHV-1) em rebanhos bovinos com atividade reprodutiva, na região Oeste do Estado do Paraná. O delineamento estatístico, amostras de soro e informações referentes às propriedades foram as empregadas para o estudo da brucelose bovina no Estado do Paraná dentro do contexto do Programa Nacional de Controle e Erradicação da Brucelose e Tuberculose. Foram avaliadas 1930 fêmeas com idade igual ou superior a 24 meses, provenientes de 295 rebanhos não vacinados contra o BoHV-1. Para o diagnóstico sorológico da infecção pelo BoHV-1, foi utilizado um ensaio imunoenzimático (ELISA) indireto. Em cada propriedade foi aplicado um questionário epidemiológico, afim de obter infor- 
mações epidemiológicas e práticas de manejo empregadas. Dos 295 rebanhos analisados, 190 foram considerados positivos para o BoHV-1, com a prevalência de rebanhos de $64,41 \%$ (I.C.95\% = 58,65-69,87\%). As variáveis consideradas fatores de risco para a infecção pelo BoHV1 na análise de regressão logística multivariada foram: i) número ( $\geq 23)$ fêmeas com idade $\geq 24$ meses ( $O R=2,22$; IC: $1,09-4,51)$; ii) compra de reprodutores $(\mathrm{OR}=2,68$; IC: $1,48-4,82)$; iii) uso de pastagens comuns $(\mathrm{OR}=5,93$; IC: 1,31-26,82); iv) histórico de abortamento nos últimos 12 meses (OR=2,37; IC: 1,09-5,16); v) presença de animais silvestres (OR=8,86; IC: 1,11-70,73). Estes resultados indicam que a infecção pelo BoHV-1 está amplamente distribuída na região estudada e que fatores relacionados às características das propriedades e ao manejo estão associados à infecção.

TERMOS DE INDEXAÇÃO: Prevalência, epidemiologia, fator de risco, herpesvírus bovino 1, ELISA indireto.

\section{INTRODUÇÃO}

O herpesvírus bovino 1 (BoHV-1) é considerado um dos principais patógenos de bovinos sendo responsável por grandes prejuízos econômicos à exploração pecuária (Kirkbride 1985). O BoHV-1 pertence à família Herpesviridae, subfamília Alphaherpesvirinae e é subdividido nos subtipos BoHV-1.1, isolados de problemas respiratórios, reprodutivos e conjuntivites, e BoHV-1.2, mais freqüentemente isolados em infecções genitais (vulvovaginite/ balanopostite pustular infecciosa-IPV/BPV) (Metzler et al. 1985, Magyar et al. 1993).

As infecções pelo BoHV-1 podem contribuir com reduções consideráveis nos índices de reprodução dos rebanhos infectados. Na dependência do período gestacional e das estruturas envolvidas, a infecção pode determinar, mortalidade embrionária precoce e/ou tardia, com repetição de cio a intervalo regular ou irregular, abortamento, natimortalidade e o nascimento de bezerros fracos. O aparelho reprodutivo também é bastante susceptível aos efeitos da infecção pelo BoHV-1, podendo ocorrer quadros de vulvovaginite, endometrite, salpingite e ooforite, que apresentam a infertilidade temporária como principal conseqüência (Bowen et al. 1985, Kirkbride 1985, Miller 1991, Takiuchi et al. 2005).

O BoHV-1, assim como outros membros da subfamília Alphaherpesvirinae, estabelece infecção latente em gânglios sensoriais, podendo ser periodicamente reativado sob condições de estresse ou tratamentos com corticóides (Ackermann 1982). O vírus em latência não é detectado por procedimentos virológicos convencionais e o animal pode apresentar subseqüentes e intermitentes episódios de excreção viral, não acompanhados de sinais clínicos, resultando na disseminação e perpetuação da infecção nos rebanhos (Pastoret et al. 1982).

O BoHV-1 está amplamente distribuído e com alta freqüência em rebanhos bovinos de todo o mundo (Mickelsen \& Evermann 1994). Evidências sorológicas demonstram a presença, bem como a alta freqüência, das infecções pelo BoHV-1 também nos rebanhos brasileiros. Dados regionais, obtidos a partir de inquéritos sorológicos, revelam a expressiva disseminação do vírus em rebanhos de corte e leite. Mueller et al. (1981) detectaram 42,2\% de animais reagentes no Estado de São Paulo. No Rio Grande do Sul foram descritas freqüências de soropositividade de $81,7 \%$ (Ravazzolo et al. 1989), 31,9\% (Vidor et al. 1995) e 18,8\% (Lovato et al. 1995). Takiuchi et al. (2001) verificaram uma freqüência de animais soropositivos para o BoHV-1 variando entre 52,4 e $81,7 \%$, em rebanhos não vacinados, provenientes dos estados de São Paulo, Paraná, Rondônia, Mato Grosso do Sul, Mato Grosso e Goiás.

No Estado do Paraná, em um estudo considerando propriedades com histórico de problemas reprodutivos, $41,9 \%$ dos animais e $90,5 \%$ dos rebanhos com aptidão leiteira foram positivos para o BoHV-1. Em rebanhos de corte, a freqüência de animais sororreagentes foi $50,8 \%$, com $100 \%$ de rebanhos positivos (Médici et al. 2000).

Os estudos realizados no Paraná, envolvendo a epidemiologia do BoHV-1 se restringiram a propriedades com histórico de problemas reprodutivos, e se caracterizaram pela ausência de delineamento amostral, não sendo possível estabelecer o real impacto e a freqüência dessa infecção. Com o propósito de elucidar a situação epidemiológica da infecção pelo BoHV-1 na região Oeste do Estado do Paraná, este trabalho teve o objetivo de caracterizar as propriedades com rebanhos bovinos com atividade reprodutiva, determinar a prevalência de focos e identificar os fatores de risco potencialmente associados com a infecção.

\section{População estudada}

\section{MATERIAL E MÉTODOS}

Este estudo transversal foi realizado na região Oeste do Estado do Paraná (Fig.1), de acordo com o delineamento amostral desenvolvido no estudo da soroepidemiologia da brucelose bovina no estado, no contexto do Programa Nacional de Controle e Erradicação da Brucelose e Tuberculose Bovina (PNCEBT). Esta região inclui os núcleos regionais de administração da Secretaria da Agricultura e Abastecimento (SEAB-PR) de Cascavel e Toledo, e envolve 48 municípios com 33.451 propriedades com exploração de bovídeos, 1.057 .930 bovídeos e 616.012 fêmeas com idade superior a 2 anos (Paraná 2001).

\section{Delineamento amostral}

A amostragem foi realizada em duas etapas. Primeiro, a seleção aleatória de um número pré-estabelecido de propriedades, que representam as unidades primárias de amostragem. Dentro das unidades primárias, foi amostrado de forma aleatória um número pré-estabelecido de animais (unidades secundárias), com a finalidade de determinar o estado sanitário do rebanho.

O cálculo do número de rebanhos foi determinado pelo grau de confiança do resultado, pelo nível de precisão desejado e pelo valor da prevalência esperado (Noordhuizen et al. 1997), sendo condizente com a capacidade operacional e financeira 


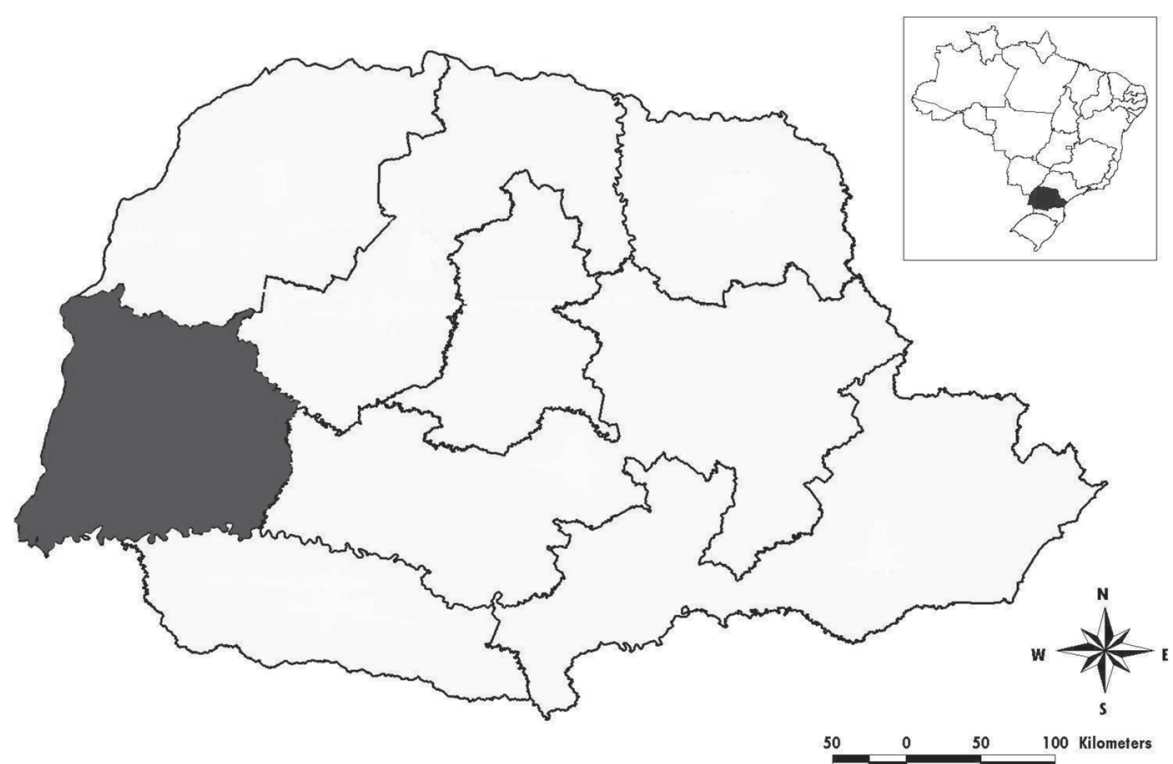

Fig.1. Mapa do Estado do Paraná demonstrando a região Oeste, alvo do presente estudo.

do Serviço Oficial do Estado do Paraná e utilizando-se a fórmula para amostras simples aleatórias, segundo Thrusfield (1995) e Noordhuizen et al. (1997):

$$
n=\frac{Z_{\alpha}^{2} \cdot \sqrt{P(1-P)}}{d^{2}}
$$

Onde:

$n$ = número de propriedades amostradas por circuito produtor;

$Z_{a}=$ valor da distribuição normal para o grau de confiança de $95 \%$;

$P=$ prevalência esperada;

$d=$ precisão, fixada em $5 \%$.

A seleção aleatória dos rebanhos, para cada circuito produtor, foi realizada a partir do cadastro de propriedades existentes junto à base da Unidade Veterinária Local correspondente. Para cada município, as propriedades existentes foram numeradas e os dados armazenados em planilhas do programa Microsoft Excel $2000^{\circledR}$. As propriedades a serem amostradas foram selecionadas aleatoriamente, considerando o número de propriedades do município e o número de propriedades amostradas no circuito produtor.

O planejamento amostral para as unidades secundárias visou estimar o número mínimo de animais a serem examinados, dentro de cada propriedade, de forma a permitir a sua classificação como foco ou não do BoHV-1.

O número de animais selecionados de cada rebanho foi determinado utilizando o programa Herdacc ${ }^{\circledR}$, version 3 (University of Guelph), considerando os valores de sensibilidade e especificidade agregada dos procedimentos de diagnóstico, prevalência intra-rebanho e erro padrão (Paraná 2001).

Em rebanhos constituídos por até 99 fêmeas, com idade igual ou superior a 24 meses, foram amostrados 10 animais ou todas as fêmeas nesta faixa etária nos rebanhos com menos de 10 animais. Em rebanhos constituídos por mais de 99 fêmeas, foram amostradas 15 fêmeas (Paraná 2001). A seleção dos animais dentro da propriedade foi aleatória utilizando-se dois métodos, a amostragem aleatória simples ou a aleatória sistemática.

Foram analisadas um total de 1930 fêmeas com idade $\geq 24$ meses, provenientes de 295 rebanhos não vacinados contra o BoHV-1.

Colheita da amostras de sangue e dados epidemiológicos

Os trabalhos a campo consistiram na colheita de sangue e preenchimento de um questionário epidemiológico. A colheita de sangue foi realizada por médicos veterinários e técnicos da SEAB-PR, no período de dezembro de 2001 a julho de 2002, por meio de punção da veia jugular utilizando agulha descartável estéril e tubo com vácuo, previamente identificado. As amostras de soro obtidas foram armazenadas em microtubos de plástico e congeladas a $-20^{\circ} \mathrm{C}$. O questionário epidemiológico foi aplicado em todas as propriedades selecionadas e teve por objetivo obter informações de sistemas de produção e de manejo.

\section{Teste sorológico}

Para o diagnóstico sorológico da infecção pelo BoHV-1 foi utilizado um ensaio imunoenzimático (ELISA) indireto.

Células MDBK (Madin-Darby bovine kidney) foram utilizadas para a produção do antígeno (BoHV-1) e para a elaboração das técnicas de soroneutralização e ELISA indireto. As células foram cultivadas em meio Dulbecco modificado (DMEM, Invitrogen, EUA), suplementado com $7 \%$ de soro fetal bovino (SFB, Invitrogen, EUA) livre de micoplasmas e vírus, $55 \mathrm{mg} / \mathrm{mL}$ de gentamicina (Sigma ${ }^{\circ}$ Co., EUA), $2,5 \mathrm{mg} / \mathrm{mL}$ de anfotericina B (Sigma® Co., EUA) e monitoradas pela técnica da RT-PCR quanto à ausência do vírus da diarréia viral bovina, de acordo com Pilz et al. (2007).

Para a produção do BoHV-1 foi utilizada a estirpe Los Angeles (LA; Madin et al. 1956) amplificada em cultivo celular em meio DMEM suplementado com $1 \%$ SFB. O título viral da suspensão foi calculado em dose infecciosa $50 \%$ para cultura de tecidos (50\% tissue culture infective doses - TCID 50 ). O BoHV1 foi utilizado tanto para a produção de antígeno para a técnica de ELISA indireto quanto para a realização da técnica de SN. O 
método utilizado para a produção de antígeno-BoHV-1 foi o descrito por Ferreira et al. (2005). A microtécnica de SN (Bitsch 1978) foi realizada para verificar a presença ou ausência de anticorpos para o BoHV-1 nos soros sangüíneos de referência, positivos e negativos, utilizados para determinação do ponto de corte e na validação do ELISA indireto para a partida de antígeno produzida.

A técnica de ELISA indireto foi realizada de acordo com o método descrito por Ferreira et al. (2005).

Para minimizar as variações dos resultados da densidade óptica (DO) obtidos em cada microplaca, a DO de cada soro foi expressa como valor de R (Relação). A determinação do valor de $\mathrm{R}$ foi calculada com base nas DOs de 10 soros controles positivos e 10 soros controles negativos, segundo Biondi et al. (1996). Foi obtido nos soros negativos o maior valor de $R$ de 0,102 . O ponto de corte foi definido em 0,230 , considerando $\mathrm{O}$ maior valor de $\mathrm{R}$ acrescido de 3 desvios padrão.

A determinação da sensibilidade e especificidade do ELISA indireto foi realizada de acordo com a metodologia descrita por Coggon et al. (1983). Foram utilizados 50 soros positivos e 50 soros negativos na SN, obtendo-se a sensibilidade de $98 \%$ e especificidade de $93 \%$.

\section{Análise de dados}

As informações dos questionários, assim como o resultado da sorologia e a condição da propriedade, foram armazenadas num banco de dados utilizando o programa Microsoft Access $₫$. A propriedade foi considerada positiva (foco) para a presença do BoHV-1 se apresentasse pelo menos um animal positivo em propriedades com até sete fêmeas; dois animais em rebanhos de 8-99 fêmeas e três animais em propriedades com mais de 99 fêmeas. Estes critérios foram estabelecidos utilizando o programa Herdacc ${ }^{\circledR}$, version 3 (University of Guelph) considerando o tamanho da população, prevalência intra-rebanho de 50\%, sensibilidade e especificidade do teste de diagnóstico utilizado (ELISA indireto), de forma a obter sensibilidade e especificidade de rebanho superiores a $90 \%$.

Considerando-se que a amostra de unidades primárias no circuito produtor foi aleatória sistemática (Cochran 1977), a prevalência aparente de focos do BoHV-1 foi calculada utilizando-se como parâmetros o número de focos e o número de propriedades amostradas (Dean et al. 1994). Os cálculos das prevalências de focos e os respectivos intervalos de confiança foram realizados com o auxílio do programa Epilnfo 6.04d (Dean et al. 1994).

As variáveis relacionadas no questionário epidemiológico permitiram o estudo dos fatores de risco. Dentre elas, foram analisadas como possíveis fatores de risco: tipo de criação; uso de inseminação artificial; raça predominante; número total de fêmeas existentes; número de fêmeas com idade $\geq 24$ meses; presença de espécies silvestres de vida livre; destino de fetos e placentas; compra ou venda de machos e/ou fêmeas para reprodução; pastagens em comum com outras propriedades; prática de aluguel de pasto; piquete separado para fêmeas na fase de parto e/ou pós-parto; e assistência veterinária.

As categorias das variáveis foram organizadas de modo a apresentarem-se em escala crescente de risco, segundo informações da literatura (Kahrs 1977, Wyler et al. 1989, Wentink et al. 1993, Van Schaik et al. 1998, Van Schaik et al. 2002). Quando necessário, realizou-se a recategorização dessas variáveis. A categoria de menor risco foi considerada como base para a comparação das demais categorias. As variáveis quantitativas foram recategorizadas em quartis.
A análise univariada foi realizada para verificar a associação entre o status do rebanho para o BoHV-1 (ausência de animais positivos $=0$; presença de um, dois ou três animais soropositivos, de acordo com os critérios descritos anteriormente $=1$ ) e variáveis de risco, utilizando o teste de $\chi^{2}$ ou teste exato de Fisher. As variáveis com valor de $p<0,2$ na análise univariada foram incluídas na análise de regressão logística multivariada (Hosmer \& Lemeshow 1989). As análises foram realizadas utilizando o programa SPSS version 9.0 (SPSS Inc. 1999a).

\section{RESULTADOS}

\section{Caracterização da amostra}

O número de animais nas propriedades selecionadas variou entre 1 e 3077, apresentando mediana de 15 animais. A dispersão do número de bovinos, segundo o sistema de exploração zootécnica das propriedades selecionadas está apresentada na Fig.2.

$\mathrm{Na}$ amostra estudada, $76,9 \%$ das propriedades de corte eram de criação extensiva, com predomínio (50\%) de raças zebuínas. A aquisição de animais para a reprodução era realizada em $71 \%$ das propriedades, sendo $65,4 \%$ proveniente diretamente de outras fazendas.

Dos rebanhos leiteiros amostrados, as criações intensivas predominaram em $60 \%$, com $48,5 \%$ dos rebanhos constituídos por raças européias especializadas na produção de leite. A compra de reprodutores era realizada por $35,6 \%$ das propriedades, sendo $24,5 \%$ diretamente de outras propriedades. A média de produção na região é de 61,09L/leite/dia.

As propriedades mistas caracterizaram-se por criações extensivas $(63,1 \%)$, com predomínio $(73,9 \%)$ de animais de composição racial mista. A inseminação artificial era utilizada em $15,3 \%$ das propriedades e $11,7 \%$ apresenta-

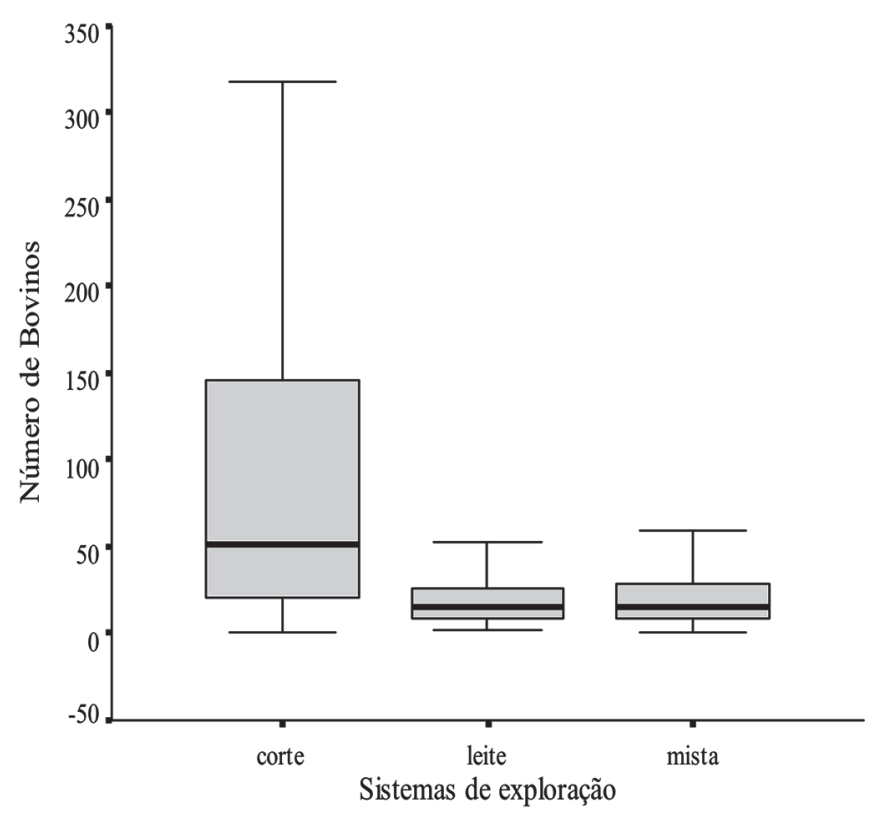

Fig.2. Diagrama de blocos mostrando a dispersão do tamanho dos rebanhos de acordo com o sistema de exploração na região Oeste do Estado do Paraná. 


\section{Quadro 1. Prevalência aparente de focos do BoHV-1 estratificada por tipo de exploração na região Oeste do Estado do Paraná}

\begin{tabular}{ccccc}
\hline \multirow{2}{*}{$\begin{array}{c}\text { Sistemas de } \\
\text { exploração }^{\mathrm{a}}\end{array}$} & $\begin{array}{c}\text { Propriedades } \\
\text { amostradas }\end{array}$ & $\begin{array}{c}\text { Propriedades } \\
\text { positivas }\end{array}$ & \multicolumn{2}{c}{ Prevalência } \\
\cline { 3 - 5 } & & $\%$ & IC 95\% \\
\hline Corte & 25 & 22 & 88,00 & {$[68,78-97,45]$} \\
Leite & 160 & 100 & 62,50 & {$[54,51-70,02]$} \\
Misto & 109 & 67 & 61,47 & {$[51,66-70,63]$} \\
\hline
\end{tabular}

a Uma propriedade não informou o tipo de exploração.

b Intervalo de confiança de $95 \%$.

vam mecanização de ordenha. A compra de reprodutores era realizada em $37,8 \%$, predominantemente de outras propriedades.

\section{Prevalência de propriedades positivas}

Dos 295 rebanhos analisados, 190 foram positivos para o BoHV-1, representando uma prevalência de $64,41 \%$ (I.C.95\% = 58,65-69,87\%).

No Quadro 1 estão apresentados os dados de prevalência de focos de BoHV-1 segundo o sistema de exploração zootécnica na região Oeste do Estado do Paraná.

\section{Análise dos fatores de risco}

No Quadro 2 estão demonstradas as variáveis relacionadas às características de propriedades e de manejo mais associadas à presença ou ausência da infecção pelo BoHV1 nos rebanhos da região Oeste do Estado. Destas variáveis selecionadas, foram considerados fatores de risco na análise de regressão logística multivariada: i) número $(\geq 23)$ fêmeas com idade $\geq 24$ meses ( $p=0,027$ ); ii) compra de reprodutores ( $p=0,001)$; iii) pasto comum ( $p=0,021)$; iv) histórico de aborto nos últimos 12 meses $(p=0,030)$ e v) presença de animais silvestres ( $p=0,040)$ (Quadro 3).

Nas propriedades especializadas na pecuária de corte, não houve associação das variáveis estudadas com a presença do BoHV-1 na análise de regressão logística multivariada. Nos rebanhos leiteiros, o fator de risco identificado na análise de regressão logistica multivariada foi compra de reprodutores (OR=2,110; IC: 1,037-4,293), e nas propriedades de exploração mista o número $\geq 12$ fêmeas ( $\geq 24$ meses) na propriedade (OR=7,738; IC: 2,164 27,676).

\section{DISCUSSÃO}

No período e região estudados, foi verificada uma prevalência de focos do BoHV-1 de 64,41\% (I.C.95\% = $58,65-69,87 \%)$. No Estado do Paraná, os trabalhos realizados anteriormente para o estudo epidemiológico do BoHV-1 não foram caracterizados por delineamento amostral. Um estudo envolvendo propriedades com problemas reprodutivos demonstrou a freqüência de $92,6 \%$ de rebanhos positivos (Médici et al. 2000).

Barbosa et al. (2005) estudaram três estratos no Estado de Goiás, caracterizados pelos tipos de exploração corte, leite e misto, utilizando como base para o cálculo das amostras, o delineamento do PNCETB. Foi verificada
Quadro 2. Distribuição das variáveis analisadas como possíveis fatores de risco para o BoHV-1 em rebanhos bovinos da região Oeste do Estado do Paraná

\begin{tabular}{|c|c|c|c|}
\hline \multirow[t]{2}{*}{ Variáveis $\underline{\underline{a}}$} & \multirow{2}{*}{$\begin{array}{l}\text { Rebanhos } \\
\text { avaliados }\end{array}$} & \multicolumn{2}{|c|}{$\mathrm{P}$} \\
\hline & & $\begin{array}{c}\text { Negativo } \\
(n=105)\end{array}$ & $\begin{array}{l}\text { Positivo } \\
(n=190)\end{array}$ \\
\hline \multicolumn{4}{|c|}{ Relacionadas à população e propriedades } \\
\hline Tipo de criação & & & 0,344 \\
\hline (1) extensivo ${ }^{b}$ & 58 & 91 & \\
\hline (2) semi-confinado / confinado & 47 & 93 & \\
\hline Tipo de exploraçãoc & & & 0,035 \\
\hline (1) leite b & 60 & 100 & \\
\hline (2) corte & 3 & 22 & \\
\hline (3) mista & 42 & 67 & \\
\hline Raça predominante & & & 0,483 \\
\hline (1) puras & 43 & 69 & \\
\hline (2) outras & 59 & 113 & \\
\hline Número de fêmeas bovinas ${ }^{c}$ & & & 0,004 \\
\hline$(0)<23$ fêmeas ${ }^{b}$ & 101 & 162 & \\
\hline (1) ${ }^{3} 23$ fêmeas & 4 & 28 & \\
\hline Número de fêmeas acima de 24 me & eses ${ }^{\mathrm{C}}$ & 0,006 & \\
\hline$(0)<13$ fêmeas ${ }^{b}$ & 99 & 158 & \\
\hline (1) ${ }^{3} 13$ fêmeas & 6 & 32 & \\
\hline \multicolumn{4}{|l|}{ Relacionadas a fatores de manejo } \\
\hline Presença de animais silvestres ${ }^{\mathrm{C}}$ & & & 0,008 \\
\hline (0) nãob & 104 & 174 & \\
\hline (1) $\operatorname{sim}$ & 1 & 16 & \\
\hline Uso da inseminação artificial ${ }^{\mathrm{C}}$ & & & 0,020 \\
\hline (0) só inseminação artificial ${ }^{b}$ & 21 & 32 & \\
\hline \multicolumn{2}{|c|}{ (1) inseminação artificial / monta natural } & 24 & 22 \\
\hline (2) não usa & 58 & 131 & \\
\hline Compra animais para reproduçãoc & & 0,000 & \\
\hline (0) nãob & 79 & 98 & \\
\hline (1) $\operatorname{sim}$ & 24 & 90 & \\
\hline \multicolumn{3}{|l|}{ Vende animais para reproduçãoc } & 0,026 \\
\hline (0) nãob & 95 & 157 & \\
\hline (1) sim & 7 & 30 & \\
\hline \multicolumn{3}{|l|}{ Destino do aborto } & 0,618 \\
\hline (0) enterra/joga/queima ${ }^{b}$ & 37 & 60 & \\
\hline (1) deixa produtos de abortos na & a pastagem & 23 & 44 \\
\hline \multicolumn{3}{|c|}{ Aluguel pasto ${ }^{C}$} & 0,043 \\
\hline (0) nãob & 101 & 170 & \\
\hline (1) $\operatorname{sim}$ & 4 & 20 & \\
\hline \multicolumn{3}{|l|}{ Pasto comum ${ }^{\mathrm{C}}$} & 0,005 \\
\hline (0) nãob & 103 & 169 & \\
\hline (1) $\operatorname{sim}$ & 2 & 21 & \\
\hline \multicolumn{3}{|l|}{ Piquetes de parição ${ }^{C}$} & 0,079 \\
\hline (0) nãob & 89 & 146 & \\
\hline (1) $\operatorname{sim}$ & 13 & 39 & \\
\hline \multicolumn{3}{|l|}{ Assistência veterinária } & 0,275 \\
\hline (0) $\operatorname{sim}^{b}$ & 56 & 90 & \\
\hline (1) não & 41 & 87 & \\
\hline \multicolumn{4}{|l|}{ Relacionadas a fatores biológicos } \\
\hline Presença de abortoc & & & 0,004 \\
\hline (0) nãob & 92 & 144 & \\
\hline (1) $\operatorname{sim}$ & 10 & 45 & \\
\hline
\end{tabular}

a Algumas perguntas não foram respondidas pelos proprietários.

b Categoria baseline.

${ }^{c} p<0,20$ na análise univariada e incluídas no modelo de regressão logística multivariada.

prevalência de focos do BoHV-1 de 98,5\% (I.C.95\% = 97,5$99,2 \%)$, estimativa que se assemelha a estudos em propriedades com problemas reprodutivos. Considerando que a amostragem de propriedades e animais foi aleatória, a prevalência estimada de focos é consideravelmente mais 


\begin{abstract}
Quadro 3. Modelo final de regressão logística multivariada dos fatores de risco associados ao BoHV-1 em rebanhos com atividade reprodutiva da região Oeste Estado do Paraná
\end{abstract}

\begin{tabular}{lccc}
\hline \multicolumn{1}{c}{ Variáveis } & $P$ & OR & IC 95\% \\
\hline Número $^{3} 13$ fêmeas acima de 24 meses & 0,027 & 2,222 & {$[1,095 ; 4,510]$} \\
Compra de reprodutores & 0,001 & 2,679 & {$[1,488 ; 4,824]$} \\
Pasto comum com outras propriedades & 0,021 & 5,931 & {$[1,312 ; 26,816]$} \\
Histórico de aborto nos últimos 12 meses & 0,030 & 2,370 & {$[1,088 ; 5,164]$} \\
Presença de animais silvestres & 0,040 & 8,858 & {$[1,109 ; 70,733]$}
\end{tabular}

$\mathrm{R}^{2}=21,0 \%$.

alta que a determinada no presente trabalho. Esta diferença pode ser explicada, parcialmente, pelo delineamento utilizado, em que foi realizada a amostragem eqüitativa de propriedades nos diferentes tipos de exploração. Propriedades de corte se caracterizam por grandes rebanhos e geralmente apresentam maior prevalência do BoHV-1 em relação aos outros sistemas de exploração (Médici et al. 2000, Melo et al. 2002, Faria et al. 2003). No presente estudo, as propriedades de corte corresponderam a apenas $8,5 \%$ do total de propriedades amostradas.

A prevalência de rebanhos positivos para o BoHV-1, estratificada por tipo de exploração na região Oeste do Estado do Paraná, demonstrou uma maior prevalência (88\%) em rebanhos especializados na pecuária de corte. Estudos realizados em rebanhos de corte com problemas reprodutivos nos Estados do Rio Grande do Sul (Vidor et al. 1995) e Paraná (Médici et al. 2000), encontraram freqüências de $71,3 \%$ e $100 \%$, respectivamente. Uma característica no manejo deste tipo de exploração pode estar relacionada a menor taxa de reposição das matrizes em relação às propriedades leiteiras. Com isso, a freqüência da infecção nos rebanhos de corte pode ser influenciada, principalmente, pela permanência de animais soropositivos no plantel por maior período de tempo.

As propriedades de corte selecionadas neste trabalho apresentaram os maiores (mediana $=51$ ) rebanhos da amostra e $71 \%$ informaram a compra de reprodutores. Vários autores citam a compra de animais em período de incubação ou nas fases aguda ou latente da infecção pelo vírus como principal fator de introdução do BoHV-1 no rebanho (Msolla et al. 1981, Pastoret et al. 1984). Desta forma, as propriedades abertas apresentariam um maior risco de infecção pelo BoHV-1.

A prevalência de focos do BoHV-1 em rebanhos de leite e misto foi de $62,50 \%$ (I.C. $95 \%=54,51-70,02 \%)$ e $61,47 \%$ (I.C.95\% $=51,66-70,63 \%)$, respectivamente. Estes resultados são semelhantes aos obtidos por Lovato et al. (1995) em nove bacias leiteiras do Estado do Rio Grande do Sul, em que verificaram a prevalência de propriedades positivas de 54,5\%. Médici et al. (2000) analisando rebanhos leiteiros com problemas reprodutivos no Estado do Paraná, verificaram a freqüência de $90,5 \%$.

A diferença entre as prevalências encontradas em propriedades de corte e leite, poderia ser também explicada pelo manejo reprodutivo empregado nos dois sistemas de produção. O sêmen é uma das principais vias de eliminação do vírus, e a utilização da monta natural como método de reprodução envolveria maior probabilidade de infecção comparada à inseminação artificial. Nas centrais de inseminação artificial, normas de controle sanitário são exigidas com o objetivo de garantir a ausência de microrganismos patogênicos no sêmen. Das propriedades de corte amostradas nesta região, 92\% utilizavam apenas a monta natural como método de reprodução, e nos rebanhos de leite este manejo era utilizado em $54,6 \%$ das propriedades selecionadas.

A análise multivariada dos fatores de risco para a infecção pelo BoHV-1 em rebanhos bovinos da região oeste do Estado do Paraná demonstrou que propriedades com número $\geq 13$ de fêmeas ( $\geq 24$ meses) $(p=0,027)$ possui maiores chances de serem positivas para o BoHV-1 que propriedades com rebanhos menores. Essa variável se manteve no modelo na análise das propriedades de exploração mista. Miller (1991) e McDermott et al. (1997) reportaram que rebanhos maiores, ou com alta densidade de animais, estão associados à alta probabilidade de infecção pelo BoHV-1. A associação entre o tamanho do rebanho e a soropositividade para o BoHV-1 pode ser atribuída a outras variáveis, fortemente relacionadas com 0 tamanho de rebanho, como a freqüência de compra de animais, participação em eventos agropecuários, visitas profissionais e presença de trabalhadores regulares e temporários nas propriedades (Van Schaik et al. 1998).

A compra de reprodutores $(p=0,001)$ foi identificada neste estudo como fator de risco para a doença. Van Schaik et al. (1998) demonstraram que propriedades que compram animais teriam 3,5 vezes mais chances de serem positivas que propriedades fechadas, considerando uma média de compra de 4,5 animais por ano. Esses dados evidenciam a importância dessa variável, quando a aquisição é realizada sem controle sanitário, como fator de introdução da doença em propriedades livres.

O intercâmbio de animais entre propriedades pode favorecer o contato entre susceptíveis e infectados. A transmissão pode ocorrer por contato com secreções nasais de animais infectados e inalação de aerossóis contaminados, por transmissão venérea ou indiretamente através de água e alimentos contaminados (Engels \& Ackermann 1996). Neste estudo, propriedades que utilizavam pastagens em comum com outras propriedades apresentaram 5,9 vezes mais chances de serem positivas do que rebanhos que não praticavam esse manejo.

Embora a transmissão interespécie não seja considerada importante na disseminação do vírus, outras espécies animais podem atuar como possíveis reservatórios. Cervídeos inoculados experimentalmente com o BoHV-1 apresentaram quadros respiratórios e eliminação intermitente do vírus em animais imunodeprimidos (Thorsen et al., 1977). A presença de animais silvestres $(p=0,019)$ identificada como fator de risco, evidencia a possibilidade de contato desses animais com bovinos da região Oeste do estado. Na região estudada está localizado o 
Parque Nacional do Iguaçu, e quatorze municípios avaliados estão localizados no entorno do parque. Aguirre et al. (1995) realizaram um estudo sorológico em cervídeos silvestres em parques nacionais nos EUA e detectaram soropositividade para o BoHV-1 de $32 \%$ para a espécie mule deer e $46 \%$ para a espécie wapiti. No Brasil, um estudo sorológico para o BoHV-1 foi realizado em cervos do pantanal da região do Pontal do Paranapanema. Foram avaliados 121 soros pela técnica de $\mathrm{SN}$, obtendo $2,5 \%$ de animais sororreagentes com títulos de até 128 (Alfieri 2007, comunicação pessoal).

O abortamento é a manifestação clínica de diversas enfermidades, inclusive da Rinotraqueíte Infecciosa Bovina. Neste estudo, o histórico de aborto foi associado à positividade de rebanhos ao BoHV-1, demonstrando que na região estudada esse vírus pode ser o agente etiológico e deve ser incluído no diagnóstico diferencial de problemas reprodutivos.

A alta prevalência de focos do BoHV-1 nos rebanhos, no período e região geográfica avaliados, indica que o vírus está amplamente distribuído, principalmente nos rebanhos de corte. A análise de fatores de risco associados à infecção pelo BoHV-1 na região Oeste do estado indica que as medidas de controle devem focar nos cuidados referentes à compra de animais e desestimular 0 contato indireto entre propriedades. A introdução de animais em propriedades livres deve ser precedida da realização de testes sorológicos e medidas rígidas de quarentena. Rebanhos livres devem evitar contato direto e indireto com bovinos originados de rebanhos que possuem histórico sanitário desconhecido, a fim de reduzir de forma considerável o risco de introdução do vírus.

Os dados epidemiológicos obtidos neste estudo poderão auxiliar a planificação de estratégias de controle fundamentada nos resultados da análise dos fatores de risco associados à infecção pelo BoHV-1 na região Oeste do Estado do Paraná.

Agradecimentos.- Os autores agradecem à Secretaria de Agricultura e Abastecimento do Estado do Paraná (SEAB-PR) e ao Departamento de Defesa Animal do Ministério da Agricultura, Pecuária e Abastecimento (MAPA) pelo auxílio no delineamento amostral, colheita de amostras e dados epidemiológicos, e ao Departamento de Medicina Veterinária Preventiva e Saúde Animal (VPS-USP) pelo auxílio na elaboração do questionário epidemiológico e análise dos dados. Este trabalho teve o suporte financeiro concedido pela CAPES, CNPq, Finep e Fundação Araucária (FAP/PR).

\section{REFERÊNCIAS}

Ackermann M., Peterhans E. \& Wyler R. 1982. DNA of bovine herpesvirus 1 in trigeminal ganglia of latently infected calves. Am. J. Vet. Res. 4:36-40.

Aguirre A.A., Hansen D.E., Starkey E.E. \& McLean R.G. 1995. Serologic survey of wild cervids for potential disease agents in selected national parks in the United States. Prev. Med. Vet. 21:313-322.

Barbosa A.C.V.C., Brito W.M.E.D. \& Alfaia B.T. 2005. Soroprevalência e fatores de risco para a infecção pelo herpesvírus bovino tipo 1 (BHV1) no Estado de Goiás, Brasil. Ciência Rural 35(6):1368-1373.

Biondi G.F., Mucciolo R.G., Nunes C.M. \& Richtzenhain L.J. 1996. Immunodiagnosis of swine cysticercosis by indirect Elisa employing a heterologous antigen from Taenia crassiceps metacestode. Vet. Parasitol. 64:261-266.

Bowen R.A., Elsden R.P. \& Seidel S.E. 1985. Herpesvirus bovine type 1-abortion. Am. J. Vet. Res. 46:1095-1097.

Bitsch V. 1978. The modification of the infectious bovine rhinotracheitis virus serum neutralization test. Acta Vet. Scan. 19:497-505.

Cochran W.G. 1997. Sampling techniques. $3^{a}$.ed. John Wiley \& Sons, New York. 428p.

Coggon T., Rose G. \& Barker D.J. 1983. Measurement, error and bias, p.20-25. In: Coggon T., Rose G. \& Barker D.J. (ed.), Epidemiology for the Unitiated. $3^{\mathrm{a}}$ ed. BMJ Publishing Group, London.

Dean A.G., Dean J.A., Colombier D., Brendel K.A., Smith D.C., Burton A.H., Dicker R.C., Sullivan K., Fagan R.F. \& Arner T.G. 1994. EpiInfo, Version 6: a word processing database, and statistics program for epidemiology on microcomputers. CDC, Atlanta. 601p.

Engels M. \& Ackermann M. 1996. Pathogenesis of ruminant herpesviruses infections. Vet. Microbiol. 53:3-15.

Epiinfo 6.04d. 1994. Atlanta: Center for Diseases Control and Prevention. Disponível em <http://www.cdc.gov/epiinfo/Epi6>. Acesso em: 10 jul. 2007.

Faria B.O., Freneau G.E., Brito W.M.E.D., Campos Jr A.C.P. \& Vieira S. 2003. Estudo de anticorpos contra o herpes vírus bovino tipo $1 \mathrm{em}$ municípios de entorno de Goiânia, GO. Revta Bras. Reprod. Anim. 27(3):543-545.

Ferreira M.C., Médici K.C., Alfieri A.A. \& Alfieri A.F. 2005. Desenvolvimento e avaliação de um ensaio imunoenzimático para o diagnóstico sorológico da infecção pelo herpesvírus bovino 1. Semina, Ciênc. Agr. 26(3):363-372.

Herdacc, version 3. 1995. Guelph: University of Guelph. Disponível em: $<$ http://www.vetschools.co.uk/EpiVetNet/files/herdacc.exe>. Acesso em: 10 jul. 2007.

Hosmer Jr D.W. \& Lemeshow S. 1989. Applied logistic regression. Wiley, New York. 307p.

Kahrs R.F. 1977. Infectious bovine rhinotracheitis: A review and update. J. Am. Vet. Med. Assoc. 171(10):1055-1064.

Kirkbride C.A. 1985. Mananging and outbreak of livestock abortion. 2. Diagnosis and control of bovine abortion. Vet. Med. 80(5):70-79.

Lovato L.T., Weiblein R., Tobias, F.L. \& Moraes M.P. 1995. Herpesvírus bovino tipo 1 (HVB-1): Inquérito soro-epidemiológico no rebanho leiteiro no Estado do Rio Grande do Sul, Brasil. Ciência Rural 25(3):425430 .

Magyar G., Tanyi J., Hornyák A. \& Bartha A. 1993. Restriction endonuclease analysis of Hungarian bovine herpesvirus isolates from different clinical forms of IBR/IPV and encephalitis. Acta Vet. Hung. 4(1/2):159-170.

McDermott J.J., Kadohira M., O'Callaghan C.H. \& Shoukri M.M. 1997. A comparison of different models for assessing variations in the seroprevalence of infectious bovine rhinotracheitis by farm, area and district in Kenya. Prev. Vet. Med. 32:219-234.

Médici K.C., Alfieri, A.A. \& Alfieri, A.F. 2000. Prevalência de anticorpos neutralizantes contra o herpesvírus bovino tipo 1 , decorrente de infecção natural, em rebanhos com distúrbios reprodutivos. Ciência Rural 30(2):347-350.

Melo C.B., Lobato Z.I.P., Camargos G.N., Souza N.R.S, Martins \& Leite R.C. 2002. Distribuição de anticorpos para herpesvírus bovino 1 em rebanhos bovinos. Arq. Bras. Med. Vet. Zootec. 54(6):575-580.

Metzler A.E., Matile H., Gassmann V., Engels M. \& Wyler R. 1985. European isolates of bovine herpesvirus 1: a comparison of restriction endonuclease sites, polypetides and reactivity with monoclonal antibodies. Arch. Virol. 85:57-59.

Mickelsen W.D. \& Evermann J.F. 1994. In utero infections responsible for abortions, stillbirth and birth of weak calves in beef cows. Vet. Clin. North Am., Food Anim. Pract. 10:1-13. 
Miller J.M. 1991. The effects of IBR virus infection on reproductive function of cattle. Vet. Med. 86(1):95-98.

Msolla P.M., Wiseman A. \& Selman I.E. 1981. The prevalence of serum neutralized antibodies to infectious bovine rhinotracheitis virus in Scotland. J. Hyg. 86:209-215.

Mueller S.B.K., Ikuno A.A., Machado J.S., Lima R.M.A., Richtzenhain L.J. \& Taki E.M. 1981. Prevalência de anticorpos contra o vírus da rinotraqueíte infecciosa bovina/vulvovaginite pustular infecciosa (IBR/ IPV) em bovinos do Estado de São Paulo. Biológico, São Paulo, 47(2):55-59.

Noordhuizen J.P.T.M., Frankena K., Van Der Hoofd C.M. \& Graat E.A.M. 1997. Application of Quantitative Methods in Veterinary Epidemiology. Wageningen Press, Wageningen. 445p.

Paraná. 2001. Programa Estadual de Controle e Erradicação da Brucelose e Tuberculose Animal: manual de procedimentos: estudo soroepidemiológico da brucelose bovina e bubalina. Departamento da Fiscalização, Secretaria de Estado da Agricultura e Abastecimento, Brasília. 21p.

Pastoret P., Thiry E., Brochier B. \& Derbover B. 1982. Bovid Herpesvirus 1 infection of cattle pathogenesis, latency, consequences of latency. Annu. Vet. Rec. 13:221-235.

Pilz D., Alfieri A.F., Lunardi M. \& Alfieri A.A. 2007. RT-PCR em pools de soros sanguíneos para o diagnóstico da infecção aguda e de animais persistentemente infectados pelo vírus da diarréia viral bovina. Arq. Bras. Med. Vet. Zootec. 59(1):1-7.

Ravazzolo A.P., Pizzol M.D. \& Moojen V. 1989. Evidência da presença de anticorpos para o vírus da Rinotraqueíte Infecciosa dos Bovinos, em alguns municípios do Estado do Rio Grande do Sul, Brasil. Arq. Fac. Vet. UFRGS 17:89-95.

SPSS INC. 1999a. SPSS Base 9.0 User's Guide, Chicago. 740p
SPSS.INC. 1999b. SPSS Base 9.0 User's Guide, Chicago. 1 CD-Rom.

Takiuchi E., Alfieri A.F. \& Alfieri A.A. 2001. Herpesvírus bovino tipo 1: Tópicos sobre a infecção e métodos de diagnóstico. Semina, Ciênc. Agr. 22(2):203-209.

Takiuchi E., Médici K.C., Alfieri A.F. \& Alfieri A.A. 2005. Bovine herpesvirus type 1 abortions detected by a semi-nested PCR in Brazilian cattle herds. Res. Vet. Sci. 79(1):85-8.

Thorsen J., Karstad L., Barret M.W. \& Chalmers G.A. 1977. Viruses isolated from captive and free-ranging wild ruminants in Alberta. J. Wildl. Dis. 13:74-79.

Thrusfield M. 1995. Veterinary Epidemiology. $2^{\text {nd }}$ ed. Blackwell Science, Cambridge. 479p.

Van Schaik G., Dijkhuizen A.A., Huirne R.B.M., Schukken Y.H., Nielen M. \& Hage H.J. 1998. Risk factors for existence of Bovine Herpes Virus 1 antibodies on nonvaccinating Dutch dairy farms. Prev. Vet. Med. 34:125-136.

Van Schaik G., Nielen M., Dijkhuizen A.A., Barkema H.W. \& Benedictus G. 2002. Probability and risk factors for introduction of infectious disease into Dutch SPF dairy farms: a cohort study. Prev. Vet. Med. 54(3):279-289.

Vidor T., Halfen D.C., Leite T.E. \& Coswig L.T. 1995. Herpes bovino tipo 1 (HVB-1): I. Sorologia de rebanhos com problemas reprodutivos. Ciência Rural 25(3):421-424.

Wentink G.H., Van Oirschot J.T. \& Verhoeff J. 1993. Risk of infection with bovine herpesvirus 1 (BHV1): a review. Vet. Quart. 15(1):3033.

Wyler R., Engels M. \& Schwyzer M. 1989. Infectious bovine rhinotracheitis /vulvovaginitis (BHV-1). In: Wittmann G. Herpesvirus diseases of catlle, horses and pigs. Kluwer Academic Publishers, Boston, p.1-72. 